\title{
A Study on the Operas of Jan Cikker
}

\author{
Olga Sobakina \\ The State Institute of Art Studies \\ Moscow, Russia \\ E-mail: olas2005@mail.ru
}

\begin{abstract}
Jan Cikker (1911-1989) is one of the renowned composers of Slovakia and special place in national culture is held by his operas, which remain a fairly rare phenomenon for the music of the XX century. Jan Cikker' style is distinguished by the clarity of idea, bright imagery, and inclination towards lyricism. The theme of human personality developed in many operas and combined with the national theme on the highest level of composing mastery. The special theme of Cikker's works is the interest to classical literature. The author examines the composition's principles in such operas by Cikker as Juro Janosik, Beg Gajazid, Mister Scrooge, The Resurrection, The Game of Love and Death, Coriolanus, The Verdict.
\end{abstract}

Keywords-Ján Cikker; Slovak music; Juro Jánošik; Mister Scrooge; The Resurrection; The Game of Love and Death; Coriolanus

\section{INTRODUCTION}

In the XX century Slovak composition school attained the well-deserved recognition thanks to the works of Eugen Suchoň, Ján Cikker, and Alexander Moyzes. The distinctive feature of their works became the demonstration of neofolklore aesthetics, as well as the search for a way to advance the national modern style within the framework of avantgarde techniques of the XX century. As noted by Eugen Suchon in one of the interviews, “... not to be an epigone and organically incorporate modern means into our lexiconthis was the primary goal for Slovak composers of my generation. This is why from the very beginning we looked simultaneously for ways to create national music and methods of introduction of it into the context of European art" [1]. In accordance with this idea Cikker's composing style is characteristic in the synthesis of contemporary composing techniques, but his idealistic-aesthetic foundation always remained the realization of national material expressed in melodic and rhythmic-harmonic structure. Thanks to this aspect, the specific communicativeness of his music and its inherent humanistic pathos are also evident. The creative core of Ján Cikker can be characterized by his own words: "The search of their own national language is an intrinsic trait of every national artist. National construct of musical thinking lives as the language which the person speaks and thinks. I do not recognize music that is neutral in its national regard" [2]. National theme gained a rich, artistically convincing and multifaceted embodiment in the works by Cikker. But there are two aspects of this theme that are dominant - the generalized idea of landscape in the orchestra compositions, and subjects of national history and Slovak epos in the operas and vocal-choral oeuvres. Another theme of Cikker's work is the special interest to classical literature. The ideas of improving personality, moral awakening, to which a person comes by overcoming internal conflicts, gained advancement in the operas The Resurrection (by Lev Tolstoy), The Game of Love and Death (by Romain Rolland), Coriolanus (by William Shakespeare), The Verdict (by Heinrich von Kleist). Cikker's opera works is distinguished by the genre diversity and broad amplitude of expression - from drama to comedy, original interpretation of the genre, and masterful musical embodiment.

Cikker believed that the establishment of Slovak musical culture must follow the path of perfecting professional mastery and reference to the themes of the historical past, as well as the modern life of Slovakia. This idea had a defining influence upon his composing throughout the 1940's. Cikker's likeminded ally was Alexander Moyzes, whose work also combined modern music techniques and the characteristic elements of the folk culture. Moyzes' students - Kardoš, Očenáś, and Jurovský - also saw prospects for their development in this direction.

\section{CIKKER'D EARLY OPERAS}

In the 1950's Cikker's works received wide acclaim. Overall, during this time the composer is attracted to program concepts and music that is linked to lyrics - he continues composing vocal numbers in folklore style (including choral arrangements), but his main goal - to write operas. In the Slovak opera culture the age-old problem was the lack of quality librettos. The brightest event in the opera of that time was the only Suchoň's Krútňava (1949), which Cikker considered a work of international significance. This opera became an example for Cikker, towards which he oriented himself while creating his first opera Juro Jánošík (1950-1953). While working on this opera, Cikker received assistance in form of advice from his friend, conductor Václav Talich. In 1946 Talich returned, creating the Czech Chamber Orchestra. The conductor worked in Prague and Bratislava, and was a renowned master; he actively promoted the new Slovak music. The libretto for the opera about Juro Jánošík - a hero of folk legends, and on the events of the brink of the XVII-XVIII centuries was written by Štefan Hoza. In the libretto he used folk songs, tales and ballades, but the foundation of the plot was based on historical facts. Cikker himself also actively participated in the libretto 
writing process. He held dear the folklore idea of the oeuvre, but strived to strengthen the realistic foundation of the storyline and vivid, vital images. In the Slovak tradition the creative interpretation of the events of Jánošík's life established in the XIX century and continued to develop, though the authors of the opera attempted to avoid the typical romantic layering. Cikker spent a lot of time working on the opera and polishing details. The opera has a strict three-act structure (two pictures in each act), it's stylistics have many musical "signs" of the places of actions (Slovak, "bandit", Italian dancing and songs) and the system of leit-themes and leit-motives that characterize the heroes. The choral scenes and ensembles were written with great mastery; it is no accident that Cikker was always fascinated by the area of vocal-choral work. The musical language of the opera differs in its melodic richness, the full of sound colors orchestra texture is saturated with polymelodics, and a significant place is held by the polyphonic episodes [3]. The premiere of Juro Jánošík found the great success of the stage of the Slovak national theatre on November 10, 1954. The critic and composer Ladislav Burlas noted that the creative value of the opera lies in the "mature individual musical style of Cikker, who presents an ideal synthesis of peculiarities of the national and personal compositional musical thinking. Such peculiarity is evident in the melodics of the vocal parts and the character of the orchestra presentation. The orchestra has the principal means to express the large dramatic conflicts. Even though we are talking about Cikker's first opera, in it he has proven his great talent as a dramatist and the precise understanding of the issues associated with creation of musical-scenic works" [4].

After completing the opera, Cikker vacationed in his beloved Tatra Mountains, continuing to study the national culture. Here obtained the concept for the next opera - Beg Gajazid. In a book store in Bratislava he saw a beautifully published poem by Samo Chalupka (1812-1883) "Turčin Poničan". The images of Turkish bey, Slovak woman and a child on the cover immediately captured Cikker's attention. The opera about the struggle of Slovaks with Turks was conceived as a historical drama in three acts, and continued the genre-line of Juro Jánošík. The libretto for the opera was written by Ján Smrek; being himself captivated and following composer's wishes, he created his own storyline based on the poem. The idea fascinated Cikker to such extent that by the Christmas of 1955 the opera was completed for piano. It's presentation (the premiere took place in 1957) that took place in Bratislava, Prague, Košice, Wiesbaden, Altenburg and other cities had even greater success than the production of Juro Jánošík. In the opera Cikker used the technique of working with theme that consists in extraction of any sort of motive and it's transformation into separate new themes. Reference to the Eastern themes significantly enriched the rhythmic sphere; composer often uses complex time signatures; polyrhythm; characteristic national rhythms; and the rhythmic picture often becomes conceptual, characterizing the heroes and the situation. The musical texture of the opera also differs in its polyphony (or linear development of several textural planes). The accents in such texture are created by the chords of the wind instruments; the chord structure is used in the dramatic episodes, while
Cikker uses the maximal escalation of all tones of the chord, implements sophisticated chromatic configurations and various types of chords. The conflict melodic dramaturgy based on contraposition of the Slavic and Eastern themes, which certainly beautified and enriched the musical language of the opera.

The opera Mister Scrooge (1958-1959) was written in a completely different key, written on the novella by Charles Dickens - "A Christmas Carol". Libretto for the already written opera was edited by Ján Smrek. Mister Scrooge presents a completely different genre - a chamber drama in three acts (four scenes). Starting on this opera, Cikker set a goal to master new composing techniques. The essence consisted in the linear-polyphonic development of the texture and the harmonic structures; thanks to the thematic calculation of the interval Cikker applied the serial principles (like "interval harmony"). The opera had a few ensemble scenes, and each of the heroes had their own intonation characteristics with the inherent interval composition. On the whole the declamation principle dominate in the vocal parts. Cikker's new opera was awaiting it's staging during several years - it was deemed an idealistically controversial work that does not correspond with the cultural demands and cannot be placed on the leading stage of the country. The premiere of the opera in Czechoslovakia on June 2, 1964 in the National Theatre in Prague during the festival of "Prague Spring", and was broadcasted on the television in Bratislava.

After the failure of the planned production of Mister Scrooge, Cikker was only able to overcome depression after starting on a new opera. The opera, which was based on the novel by Lev Tolstoy "Voskriesenie" ("Resurrection") and completed in 1961, became one of the highlights of composer's career. The choice of Russian story, not least bit less complicated for opera than Dickens' story, was also supported by Cikker's friends, but the composer faced the difficult task of adapting the Russian text. Analyzing the writing process of the opera, Cikker noted that a composer must be interested in the story, since the form is defined by the content of the libretto, and depends on its idealistic value and ability to move and convince by its sincerity and depth. This is the reason why Cikker was unafraid to turn to large canvases of classical literature - Tolstoy, Shakespeare, and ancient tragedy. In Tolstoy's novel he selected the storyline of personal relations between Katyusha Maslova and Neklyudov, thus the genre of the opera (also in three acts) can be defined as a melodrama. The composer wrote the libretto himself, employing consultation from Russian acquaintances (let us note that from this point forth all librettos the composer was writing himself). In The Resurrection Cikker advances the compositional techniques that he developed in the previous opera, but "Russian notes" seep through in the reference to the modal structures, which overall dominate the twelve-tone system and principle of expanded tonality. Cikker significantly enriched the vocal sphere, filling it with lyrics combined with declamation; especially interesting is the use of free recitative fragments. The Resurrection produced a vast interest in musical world and gained resonance: in Germany it was awarded the Herder Prize for 1966, and in Czechoslovakia - the Klement 
Gottwald Award. After the premiere in Prague (on May 18, 1962) and Bratislava (on September 12, 1969), the opera was also staged in other leading theatres; it is interesting to remember the production by Walter Felsenstein in the Komische Oper (Berlin).

\section{DRAMA AND COMEDY IN OPERAS BY CIKKER}

Cikker's work during these years was not limited to opera writing - he also wrote several orchestra compositions including Orchestra Sketches for the Drama (1965, on the sketch for the play "The Physicists" by Friedrich Dürrenmatt, which the composer wanted to use as the libretto for his next opera). The opera director Rennert Günther gave the composer the idea to refer to the events of the French Revolution, and Cikker chose the drama of Romain Rolland - "The Game of Love and Death", written in 1925 (the Slovak title of the opera can be also translated as "Play on Love and Death"). Over the fall of 1966 he prepared the libretto; in September he wrote the opera for piano, and in May of 1968 he completed the score. The plot of Rolland's drama attracted the composer with the parallels emerging between the events of the Jacobins dictatorship and the events of the social life of the 1950's. Cikker did not set out to create an effective work; on the contrary, the opera The Game of Love and Death was planned as a modern production with minimal props and ornamentation of a unified scenic space without curtains and lavish decorations. The modesty of the entourage had to highlight the value of human feelings and relations. As in The Resurrection, in The Game of Love and Death Cikker stopped on the main storylines of Rolland's drama; in some fragments he introduced his own text, underlining the idea of the piece the struggle of love of a married couple with insurmountable circumstances leading to their demise. Opera expresses the protest against all that destroys the human right to liberty and happiness, and is written in a genre of through-composed psychological drama, representing a chamber spectacle in single act. Its form is organized by the musical-thematic arch between opening and conclusion: dramatic opening presents the "triumph of death"; upon its material the tragic "quite" and is built, symbolizing the inevitability of the heroes' death. The symmetry of the composition is also highlighted by the parallels between the first and final dialogues of the married couple. The Game of Love and Death is one of the brightest and original opera works. The musical language of the opera is distinguished by its free development of the melodic declamation in the vocal parts, polyphony, and polymetry; its harmonic foundation is the free atonality. The colorfulness of the sound palette is also characteristic to this opera, but in an attempt to highlight the significance of the vocal part and the word as such, the composer leads the sound of the orchestra into a quite dynamic, with exception in few fragments. This technique heightens the effect of tension and fear, piercing the emotional atmosphere of the play. The premiere of The Game of Love and Death took place on August 1, 1969 on the International Opera Festival in Munich; the composer gave the right to the premiere to the director who gave him the idea for this opera - Rennert Günthe. A number of triumphal productions of The Game of Love and Death followed across Germany, where it was compared to the operas of Alban Berg.

For the 200-year anniversary of Beethoven, Cikker wrote two oeuvres - Variations of Hommage à Beethoven (1969) and the opera based on the Shakespeare's tragedy Coriolanus (1972). The overture to the opera was conceived in Beethoven's traditions (more specifically, the famous namesake overture), and performed at the "Prague Spring" festival in 1970. The opera expressed composer's negative attitude towards the events that took place on August of 1968. Cikker was never indifferent towards political events. Having experienced the World Wars, he resented any manifestation of violence. More than once the composer considered moving abroad - after he was forced to leave the theatre, and after the production of his opera Mister Scrooge was rejected. Cikker was invited to work in Genève, Amsterdam, and the United States, but he always declined, understanding that on foreign land without contact with his home culture it would be a lot more difficult [5]. The composition of Coriolanus was compared with Mussorgsky's Boris Godunov and Janáček's operas, which was due to significance of the choral episodes and clear recitation of the vocal parts, rather than political orientation. This opera preserved the traditional three-act structure that organized fourteen scenes. Cikker significantly altered many details of the story, underlining the differences in the characters of heroes fighting for justice, uncompromising in their fight for freedom, but full of humanistic feelings. The ancient theme led him to the search of expressive "clarified" musical style, to the return of the bright, figurative orchestral writing. After the completion of Coriolanus, there was a break in Cikker's opera work. He taught and wrote chamber compositions. His central work of the early 70's was Symphony 1945, written in 1974 in commemoration of the 30 years since the end of the World War II. Cikker always emphasized that he wrote his symphony on his own sincere accord, as a memory of heroic historical fact, significance of which cannot be argued. Accepting the fact that the Eastern European countries have "paid" for their liberation, he believed that another fate for the entire Central Europe is unimaginable - it would have been destroyed by the fascists.

In 1977 the composer again returns to the opera genre, turning to the story of "The Earthquake in Chile" by Heinrich von Kleist, written in 1807. The final version of the new opera received the title The Verdict and was produced on October 6 of 1979 in Bratislava, and later in Germany and the Czech Republic. The opera consists of three acts (five scenes) and yet again develops the principles of musical drama, inheriting the lines of the preceding operas. It is dedicated to the tragic love of the heroes, perishing from the religious fanaticism of the crowd. "Anger and hate accompanied all human generations, whether they sang Dies irae, ... or Hej, horeháj, dolyháj. The hate has always been the hate, and my goal was to reveal its effects. Same goes for fanaticism, which is dangerous for all. W here are the thoughts of love to our neighbors, of forgiveness of sins, of Christianturning the other cheek? My opera, perhaps, is merely a musical reflection of personal protest against trampling of human dignity and the injustice of humiliation. I 
set no other goals in The Verdict opera" [6]. Hence the opera's closing dissonating orchestral tutti expresses the composer's protest and sums up the final line of the old woman - "People, for what do you judge the innocent?" The musical value of the work is defined by the thematism related to the line of love shared by the main characters Isabel and Lorenzo. The other two dramaturgical lines - faith and religious fanaticism - create a conflict sphere, which is dominated by the development of thematism of Catholic liturgy, in particular, the sequence Dies irae. The opera is distinguished by its bright imagery, counterpoints and conflictness of the musical characteristics. In it, Cikker uses the method of growing the vocal parts from the orchestral texture and creates the unity of the sound complex. The vocal parts astonish in their diversity of techniques and means, often used polyphonically - as, for example, in the final ensemble. Despite the complexity of the vocal parts, cantilena dominates in this opera in comparison to preceding operas. It is largely due to the trend towards further clarification of the language, encompassing all of Cikker's later works. In this opera the foundation of the texture becomes the heterophony, but the process of continuous current of the music, unity of the sound complex of the orchestra and vocals, allow us to speak about work as a bright manifestation of opera symphonism.

The genre of comedy attracted the composer rather late he was 70 years old when he wrote the opera Obliehanie Bystrice (The Siege of Bystrica, 1981, based on the novel of a Hungarian comedic writer Kálmán Mikszáth); then, in 1986, he completed another musical comedy based on the satirical play of the Capek brothers - Ausdem Leben der Insekten (From the life of insects, premiered in Bratislava on October 8 of 1983). In Mikszáth's novel Cikker was attracted to the humor and the Slovak roots of the writer. The situation forces him to lay siege to Bystrica, but he will not succeed in this "unrighteous" deed. The composer chose the comedic episodes in the literary source, and united them into a logically-progressing storyline, which intertwines comedy, tragic comedy, drama, and lyrics (comedic line is decorated by the heroes' love story). The opera consists of three acts (nine scenes) and inherits two main creative directions of Cikker - the line of modern realization of folklore, and the line leading from the opera Mister Scrooge, developing the modern composing techniques. During these years Cikker periodically returned to realization of Slovak folklore in orchestral compositions; subject of the new opera created special conditions for using folklore, and not only Slovak, but also Hungarian, Gypsy, Ukrainian, and German. The opera's musical language is dominated by the SlovakMagyar intonational complexes based on the modal-diatonic structures; the composer creates new forms of scales (including atypical, with gaps of tones (eight, ten, eleven, etc.), each of which is "fixed" after one of the leit-motives). Especially saturated with folklore intonations are the first, sixth, and ninth scenes of the opera, where the composer also uses direct folklore quotes. Compared to the drama operas, the musical language of The Siege of Bystrica is distinguished by the dominance of the vocal parts. The style of the vocal parts is more natural in the used intonations, which corresponds with the comedic specificity of the storyline. It is interesting that the opera does not have choirs (they are replaced by men's ensembles) and develops the trend of the preceding operas in the reduction of the volume of the orchestra dynamics, but as in all Cikker's compositions, the orchestra is distinguished by its colorfulness. The folklore motives endowed the orchestration a refined character; in addition to that, the orchestral parts are rich with game of timbres, which add psychological meaning to the heroes' lines. The premiere of Cikker's last finished opera - From the Life of the Insects was held in 1987 Bratislava. Out of two versions of the storyline the composer picked the one, which as many of his operas (with the exception of Beg Bajazid and The Siege of Bystrica) ends with the death of the hero. Cikker's last opera became a proverb on the meaning of human life and its values - first and foremost, love and mutual help. The opera involved a large cast of performers - over 30 soloists, choir, ballet, and a grand symphonic orchestra. Its stylistics corresponds with the character of the works of these years - it's lyrical orientation and clarification of the musical language, imagery of the characteristics and precise use of dramaturgical techniques. After this opera, the composer considered opera work completed. Having started composing the opera Antigone by Sophocles' tragedy, he decided that it will not be relevant for the modern situation and destroyed the work in progress.

\section{CONCLUSION}

The work of Ján Cikker has a lasting importance for more than just the Slovak culture. His name can rightly be called alongside the founders of the modern national composing schools of Europe. It is not by accident that in 1979 the composer became the first Czechoslovakian musician to receive the UNESCO prize. Ján Cikker's oeuvres are distinguished by the clarity of concept, bright imagery, poeticism and humanism. The main theme of his work is the theme of human identity, developed in many works and shining with many facets. The composer embodied the national theme and realized the national folklore on the highest level of compositional mastery, and just as important is his role in the development of modern Slovak composing school. One could express hope that the talented and highly artistic works of Ján Cikker will also become known to our music society.

\section{REFERENCES}

[1] E. Suchoň. "To be sincere...", The Soviet Music, 1983, No. 12, p. 119.

[2] L. Polyakova. Jan Cikker: "I think that it is necessary to write music about a person, his spiritual development ...", The Soviet Music, 1971, No. 9, p. 133.

[3] L. Polyakova. "The Czech and Slovak opera in the XX century", book 2, M: The Soviet Composer, 1983.

[4] M. Palovcik. "Jan Cikker in memoirs and works ", Presov: Matus music, 1995, p. 168.

[5] J. Samko. "Jan Cikker", Bratislava: SVKL, 1955.

[6] M. Palovcik. "Jan Cikker in memoirs and works", Presov: Matus music, 1995 , p. 300. 